\title{
The effect of level of feeding, genetic merit, body condition score and age on biological parameters of a mammary gland model
}

\author{
J. R. Bryant ${ }^{1 \dagger}$, N. Lopez-Villalobos ${ }^{1}$, C. W. Holmes ${ }^{1}$, J. E. Pryce ${ }^{2}$, G. D. Pitman ${ }^{3}$ and S. R. Davis ${ }^{4}$ \\ ${ }^{1}$ Institute of Veterinary, Animal and Biomedical Sciences, Massey University, Private Bag 11-222, Palmerston North, New Zealand; ${ }^{2}$ Livestock Improvement \\ Corporation, Private Bag 3016, Hamilton, New Zealand; ${ }^{3}$ Wrightsons Solutions, 15 Tybalt Street, Stratford, New Zealand; ${ }^{4}$ ViaLactia Biosciences Ltd, PO Box 109- \\ 185, Newmarket, Auckland, New Zealand
}

(Received 1 March 2006; Accepted 5 November 2006)

\begin{abstract}
An evolutionary algorithm was applied to a mechanistic model of the mammary gland to find the parameter values that minimised the difference between predicted and actual lactation curves of milk yields in New Zealand Jersey cattle managed at different feeding levels. The effect of feeding level, genetic merit, body condition score at parturition and age on total lactation yields of milk, fat and protein, days in milk, live weight and evolutionary algorithm derived mammary gland parameters was then determined using a multiple regression model. The mechanistic model of the mammary gland was able to fit lactation curves that corresponded to actual lactation curves with a high degree of accuracy. The senescence rate of quiescent (inactive) alveoli was highest at the very low feeding level. The active alveoli population at peak lactation was highest at very low feeding levels, but lower nutritional status at this feeding level prevented high milk yields from being achieved. Genetic merit had a significant linear effect on the active alveoli population at peak and mid to late lactation, with higher values in animals, which had higher breeding values for milk yields. A type of genetic merit $\times$ feeding level scaling effect was observed for total yields of milk and fat, and total number of alveoli produced from conception until the end of lactation with the benefits of increases in genetic merit being greater at high feeding levels. A genetic merit $\times$ age scaling effect was observed for total lactation protein yields. Initial rates of differentiation of progenitor cells declined with age. Production levels of alveoli from conception to the end of lactation were lowest in 5- to 8-year-old animals; however, in these older animals, quiescent alveoli were reactivated more frequently. The active alveoli population at peak lactation and rates of active alveoli proceeding to quiescence were highest in animals of intermediate body condition scores of 4.0 to 5.0. The results illustrate the potential uses of a mechanistic model of the mammary gland to fit a lactation curve and to quantify the effects of feeding level, genetic merit, body condition score, and age on mammary gland dynamics throughout lactation.
\end{abstract}

Keywords: age, body condition, dairy cattle, genetic merit, mammary glands, nutrition.

\section{Introduction}

Biological processes of milk synthesis in the mammary gland have been studied extensively and modelled (Neal and Thornley, 1983; Dijkstra et al., 1997; Vetharaniam et al., 2003b). Yields of milk in dairy cattle and other species are largely a function of the number of mammary secretory cells and the secretory activity per cell (Knight, 1989 and 2000; Dijkstra et al., 1997; Capuco et al., 2001). The numbers of active secretory mammary cells at different stages of the lactation are determined by the balance

† E-mail: Jeremy.Bryant@agresearch.co.nz between the rates of proliferation and quiescence into non-secretory cells (Molenaar et al., 1992; Knight, 2000). Proliferation, the process where undifferentiated mammary cells progress to an active secretory state, occurs at an exponential rate from the start of gestation and reaches a maximum soon after parturition when mammary cell numbers are at their peak (Knight, 1993). Shortly after parturition, a proportion of mammary cells progress to a quiescent or resting pool of non-secretory mammary cells. These quiescent cells can either be reactivated to milksecreting mammary cells, or they can proceed to senescence which is often termed apoptosis (Molenaar et al., 1992; Wilde et al., 1997). 
The effects of nutrition, or feeding level, genetic merit, levels of body fat or age on each process of the mammary gland are not clear. Nutritional changes affect circulating levels in blood of glucose, a major precursor of milk, to the mammary gland (Pollott, 2004). Knight (2000) showed the amount of mammary tissue was directly proportional to milk yields in cows of low or high genetic merit. Similar results were obtained in a study of Jersey cattle by Davis et al. (1985). Broster and Broster (1998) reported that higher body condition scores (BCS), in the range of thin to moderate levels, generally resulted in elevated milk yields in early lactation, but they concluded the benefits of higher BCS are unclear for later lactation. Age affects milk yields, with lower potential milk yields in younger animals (Nielsen et al., 2003), which may be partially due to lower live weights in younger animals. For example, Linzell (1972) presented results within and amongst species which illustrated that both milk yield and mammary gland weight were positively correlated with live weight. Although these results illustrate the effects of nutrition, genetic merit, body fatness and age on total or daily yields, they do not provide a quantitative framework with which the effect of each factor can be simulated in a model of the mammary gland.

Vetharaniam et al. (2003b) constructed a model that simulated milk synthesis in the mammary gland by linking the effects of nutrition and genotype. Using a small data set of two Holstein Friesian genotypes managed on diets of pasture or total mixed ration, they found the estimated active population of alveoli, or milk-secreting mammary cells, throughout lactation was related to actual yields. The objectives of the present study were to utilise data from a New Zealand trial to further quantify the effects of nutrition, genetic merit, body fatness and age on the parameters in the model of the mammary gland constructed previously by Vetharaniam et al. (2003a and b).

\section{Material and methods}

\section{Mammary gland model}

The objective of this section is to give a brief introduction of the mammary gland model of Vetharaniam et al. (2003a and b). Key equations and an adapted schematic (Figure 1) are reproduced below:

$$
\begin{aligned}
& r_{p a}=k_{1} \exp \left(-k_{2} t\right) \\
& r_{a q}=k_{3} A_{t} \\
& r_{q a}=k_{4} Q_{t} \\
& r_{q s}=k_{5} Q_{t} \\
& c=\frac{k_{1} k_{3}}{k_{2}\left(k_{2}-k\right)+k_{3} k_{5}}
\end{aligned}
$$

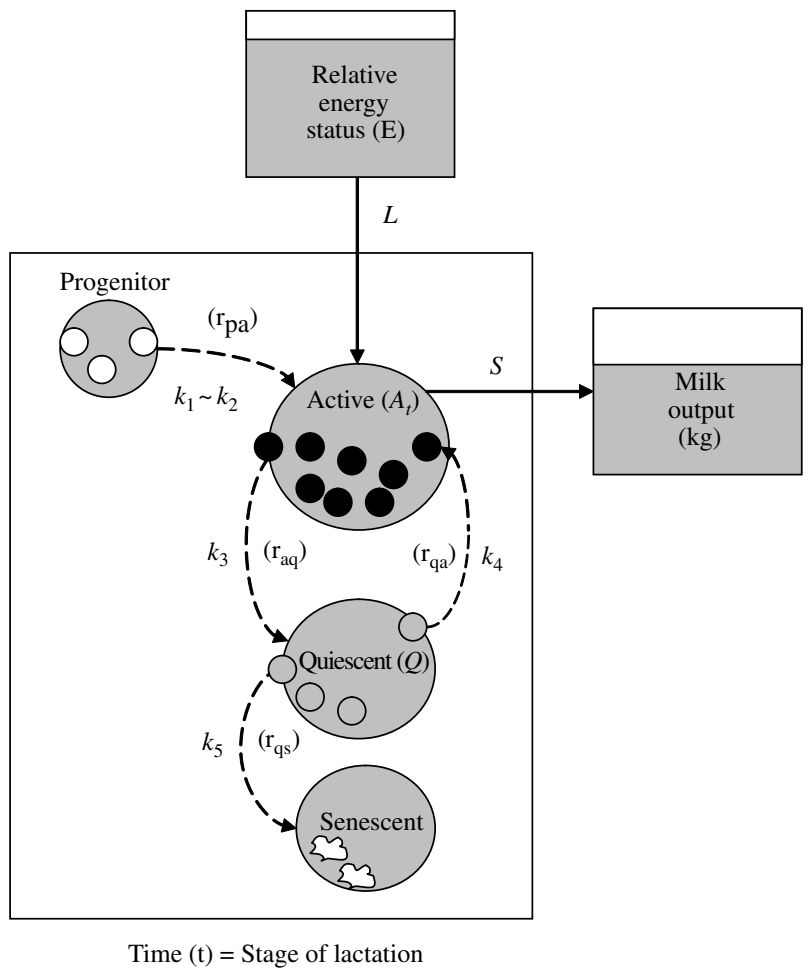

Figure 1 Schematic diagram of the mammary gland model (adapted with permission based on Vetharaniam et al. (2003a)). Abbreviations: $A_{t}=$ active secretory alveoli at time $t, Q=$ quiescent alveoli, $S=$ secretion rate per active alveoli, $r_{p a}=$ rate of differentiation from progenitor to active secretory alveoli, $r_{a q}=$ rate at which active secretory alveoli proceed to quiescence, $r_{q a}=$ rate at which quiescent alveoli are reactivated to become active secretory alveoli, and $r_{q s}=$ rate at which quiescent alveoli proceed to senescence.

$$
\begin{aligned}
& d=\frac{c}{k_{3}}\left(k_{4}+k_{5}-k_{2}\right) \\
& w_{6}=-\frac{k}{2}+\frac{1}{2} \sqrt{k^{2}-4 k_{3} k_{5}} \\
& w_{7}=-\frac{k}{2}-\frac{1}{2} \sqrt{k^{2}-4 k_{3} k_{5}} \\
& l_{6}=\frac{q_{6}}{k_{3}}\left(w_{6}+k_{4}+k_{5}\right) \\
& l_{7}=\frac{q_{7}}{k_{3}}\left(w_{7}+k_{4}+k_{5}\right) \\
& k=k_{3}+k_{4}+k_{5} \\
& q_{6}=\frac{\left(w_{7}+k_{2}\right) c+A_{0} k_{3}}{w_{6}-w_{7}} \\
& q_{7}=-\frac{\left(w_{6}+k_{2}\right) c+A_{0} k_{3}}{w_{6}-w_{7}} \\
& A_{t}=d e^{-k_{2} t}+l_{6} e^{w_{6} t}+l_{7} e^{w_{7} t}
\end{aligned}
$$




$$
\begin{aligned}
& Q=c e^{-k_{2} t}+q_{6} e^{w_{6} t}+q_{7} e^{w_{7} t} \\
& E=\frac{F I_{a}}{F I_{\max }} \\
& I=S E^{L} A_{t}
\end{aligned}
$$

In brief, the mammary gland model consists of alveoli (groups of secretory cells) in various states of activation or inactivation (Figure 1). At the start of lactation each animal has an initial pool of active alveoli, $A_{0}$. The number of active alveoli, $A_{t}$ (equation 14) at time $t$ is dependent on a series of equations (equations 1 to 13 ) with the initial condition $(t=0)$ where $A_{t}=A_{0}$. The rate of production of active alveoli by progenitor (undifferentiated) cells, $r_{p a r}$ decays exponentially throughout the lactation with an initial constant, $k_{1}$, and decay constant, $k_{2}$ (equation 1). Throughout lactation, active alveoli can proceed to a state of quiescence (non-secretory cells) with the size of the quiescent pool defined in equation 15 . The rate of quiescence of active alveoli, $r_{a q}$ is proportional to $A_{t}$ and $k_{3}$ (equation 2). The quiescent alveoli then become either, reactivated to secretory alveoli (secretory cells) or proceed to senescence. The rate of reactivation of quiescent alveoli, $r_{q a}$ is proportional to the quiescent alveoli population and a constant $k_{4}$ (equation 3 ). The rate of senescence of quiescent alveoli, $r_{q s}$ is proportional to the number of quiescent alveoli and $k_{5}$ (equation 4). The total production of alveoli from conception until the end of lactation, $A_{\text {produced }}$ is: $A_{0}+k_{1} / k_{2}$. At any stage of the lactation, milk energy output ( $l$; equation 17) is influenced by the relative energy status of the animal ( $E$; equation 16), which is a ratio of actual feed intake $\left(\mathrm{Fl}_{\mathrm{a}}\right)$ versus theoretical maximum feed intake $\left(F I_{\text {max }}\right)$, the number of active alveoli $\left(A_{t}\right)$, a theoretical maximum secretion rate $\left(S ; 3 \times 10^{-9} \mathrm{MJ} /\right.$ day based on previous data) and a nutritional response factor $(L)$ which is invoked when $E$ is less than 1.00.

\section{Animal data}

To quantify the effects of level of feeding, genetic merit, $\mathrm{BCS}$, and age on the biological parameters of the described mammary gland model, a data set was obtained from a New Zealand trial with Jersey cattle in the 1999/2000 season. Data consisted of an initial estimate of BCS around parturition and then up to 15 (herd tests carried out at 14day intervals) measurements of daily yields of milk, fat and protein per cow per lactation, and corresponding days in milk at each test. Total lactation yields of milk, fat and protein, live weight at peak lactation (22 October), days in milk and estimates of breeding values (EBV) for milk for each individual animal were also obtained. Estimates of intakes of pasture and supplements at each test were calculated from the area grazed per cow daily, pre- and postgrazing masses of pasture and supplements offered.

The Jersey cows were managed at different feeding levels: high, medium, low and very low. The corresponding estimates of average feed intakes for each feeding level group over the lactation period were 13.47, 13.02, 12.40 and $11.74 \mathrm{~kg}$ dry matter (DM) per cow per day, respectively. Initially, 40 cows were assigned to each feeding level group. Little supplement was fed, and was generally highquality pasture silage fed to all feeding level groups at rates of 2 to $3 \mathrm{~kg}$ DM per cow per day for approximately 4 weeks at the start and end of the lactation. The relative energy status, $E$, at each herd test was determined based on estimated intakes of pasture and supplements of each feeding level group divided by theoretical maximum intakes of $16 \mathrm{~kg}$ DM per cow per day (approx. $4 \%$ of live weight). The energy value per $\mathrm{kg}$ of milk was calculated from milk yields, and fat, protein and lactose component concentrations based on the equations of Dado et al. (1993).

\section{Evolutionary algorithm analyses}

To determine estimates of model parameters, $A_{0,} k_{1}, k_{2}, k_{3}$, $k_{4}, k_{5}, L$ and $A_{\text {produced }}$ for the milk yield lactation curve of each individual animal, an evolutionary algorithm add-in for Microsoft Excel ${ }^{\odot}$ called Genetic Algorithm (YearStretch, 2005) was applied to the system of equations outlined by Vetharaniam et al. (2003b). Evolutionary algorithms have proved efficient at finding the global optima in a number of agricultural models (Mayer et al., 1996; Hart et al., 1998). Evolutionary algorithms are based on the biological concepts of reproduction where two selected individuals, with different genetic codes, are 'mated' or crossed to produce the next generation. In the context of the present study, the individuals are an array of estimates of mammary gland model parameters. Over generations, or iterations, the process combines successful parameter values, which improve the fitness of the population. While crossover is the dominant genetic operation, mutation is also introduced at each mating to rediscover any potential beneficial parameter values. Through successive mating of selected individuals (arrays), the population structure tends to find a near-optimal solution (Mayer et al., 1999).

The parameter bounds specified in Table 1, were based on the estimates obtained by Vetharaniam et al. (2003b). Fitness was defined as the size of the mean prediction error (MPE) of actual compared with predicted milk yields, the smaller the better as outlined by Fuentes-Pila et al. (1996). Mayer et al. (2001) recommends a population size

Table 1 Summary of parameter bounds for the mammary gland model

\begin{tabular}{lr}
\hline \hline Mammary gland parameters & \multicolumn{1}{c}{ Bounds } \\
\hline$A_{1}\left(\times 10^{10}\right)$ & $1.0-3.0$ \\
$k_{1}\left(\times 10^{9}\right.$ per day $)$ & $0.5-2.5$ \\
$k_{2}\left(\times 10^{-1}\right.$ per day $)$ & $0.5-4.0$ \\
$k_{3}\left(\times 10^{-1}\right.$ per day) & $2.0-6.0$ \\
$k_{4}($ per day $)$ & $3.0-7.0$ \\
$k_{5}\left(\times 10^{-2}\right.$ per day $)$ & $0.01-5.0$ \\
$L\left(\times 10^{-1}\right)$ & $3.0-7.0$ \\
\hline \hline
\end{tabular}


of approximately twice the dimensionality of the problem, but not too small to ensure genetic diversity. Based on the present seven-dimensional problem, an initial population size of 50 with the 25 best arrays of parameters surviving per iteration seemed reasonable. However, MPE was reduced further when using a population size of 100 with the best 50 selected and was therefore adopted for evolutionary algorithm analyses. Mutation, which was at an automated rate in the Genetic Algorithm add-in, was used to rediscover any potential beneficial parameters values in subsequent iterations. The evolutionary algorithm ran for 50 iterations, and the parameter values that minimised MPE was then kept for each individual animal. Based on these individual parameter values, an estimate of the number of active alveoli was also obtained at peak $\left(A_{\text {peak }}\right)$ and mid to late $\left(A_{\text {mid-late }}\right)$ lactation. Peak and mid to late lactation corresponded to the test nearest to day 35 and day 150 after a cow's parturition, respectively. Pearson's correlation coefficients between $A_{0}, k_{1}, k_{2}, k_{3}, k_{4}, k_{5}, L$, $A_{\text {produced }} A_{\text {peak }}$ and $A_{\text {mid-late }}$ were also calculated to determine the association between estimated mammary gland model parameters.

\section{Multiple regression analyses}

To determine the effect of the continuous variables of feeding level (average feed intake), genetic merit (EBVs), BCS, and age (from birth) on total lactation yields of milk, fat and protein, live weight around the time of peak milk yield, days in milk, and the evolutionary algorithm derived mammary gland parameters $\left(A_{0}, k_{1}, k_{2}, k_{3}, k_{4}, k_{5}, L\right.$, $A_{\text {produced }} A_{\text {peak }}$ and $\left.A_{\text {mid-late }}\right)$, the REG procedure in the Statistical Analysis System package, version 8 (SAS, 1999) was used. The multiple regression model was:

$$
\begin{aligned}
y= & a+b_{1} F L+b_{2} F L^{2}+b_{3} G M+b_{4} G M^{2}+b_{5} B C S \\
& +b_{6} B C S^{2}+b_{7} A g e+b_{8} A g e^{2}+e
\end{aligned}
$$

where $y$ is the dependent variable, $a$ is the intercept, $b_{1}-b_{8}$ are the regression coefficients for feeding level (FL), genetic merit $(G M), B C S$ and Age as linear and quadratic effects, and $e$ is the residual error. Genetic merit was defined as the deviation in milk EBV relative to the animal in the data set with the lowest milk EBV. For each trait, a backward regression procedure was used where the nonsignificant $(P>0.10)$ effects were removed from the model. If the intercept was deemed non-significant $(P>0.10)$ it was also removed from the model.

Multicollinearity among multiple regression predictor variables, which can inflate standard errors and parameter estimates, was investigated by obtaining the variance inflation factor calculated as $1 /\left(1-R^{2}\right)$, where $R^{2}$ is the coefficient of determination from ordinary least-squares regression of a predictor variable in relation to all other predictors in the model (Phillipi, 1994). Variance inflation factors of 10 or greater were considered to indicate a problem with multicollinearity (Phillipi, 1994). This threshold was only exceeded when linear and quadratic terms of an effect were included in the selected model. In the instances where multicollinearity was detected, the ORTHOREG procedure (SAS, 1999), which accounts for multicollinearity by orthogonalising the data using a Gentleman-Givens transformation, was applied to the selected regression model to find unbiased standard errors and parameter estimates ( $\mathrm{Yu}$, 2000).

\section{Results}

Means, standard deviations and model accuracy

The parameter $k_{5}$, which influences persistency of milk yields, showed the greatest variability (Table 2 ). The degree of variability of $L$, which determines the animal response at times of nutritional stress, was low even though the pre-defined parameter space was 3.0 to $7.0 \times 10^{-1}$. The model was able to match predicted and actual milk yield values with a high degree of accuracy (Figures 2 and 3). Accuracy was greatest at the intermediate feeding levels. The threshold of 0.10 error as suggested by Fuentes-Pila et al. (1996) where there is a poor fit between actual and predicted values was not exceeded for any animals in the data set.

\section{Correlations between mammary gland parameters}

As expected the highest positive correlations $(P<0.001)$ was observed between $A_{\text {peak }}$ and $A_{\text {mid-late }}$ (Table 3). Significant negative correlations $(P<0.001)$ were observed between $A_{0}$ and $k_{1}, k_{3}$ and $k_{5}$, and $k_{4}$ and $A_{\text {produced }}$. Significant positive correlations $(P<0.001)$ were observed between $A_{0}$ and $k_{2}, k_{1}$ with $A_{\text {producedr }} A_{\text {peak }}$ and $A_{\text {mid-later }}$ $k_{3}$ and $A_{\text {producedr }}$ and $k_{5}$ and $A_{\text {peak }}$.

\section{Feeding level}

As expected, greater total lactation yields of milk, fat and protein were observed at higher feeding levels (Table 4). Contributing, to these differences in yields were an increase in lactation lengths at higher feeding levels. The rate, at which new alveoli are produced, largely determined by $k_{1}$, was affected by feeding level, with higher production rates at lower feeding levels (Table 5). The rate at which the production of new alveoli declines with time, largely determined by $k_{2}$, was highest at intermediate feeding levels. Level of feeding significantly affected the senescence rate of quiescent alveoli, $k_{5}$ (higher senescence rate $=$ reduced persistency), with the highest value at a very low feeding level. $A_{\text {produced }}$ and $A_{\text {peak }}$ were at their maximum value in the low feeding level environment.

\section{Genetic merit}

A scaling effect was observed at high feeding levels with greater gains in milk and fat yields per 1-kg increase in milk EBV observed than at low feeding levels (Table 4). The total production of alveoli from conception until the end of lactation, $A_{\text {produced, }}$ also exhibited a genetic merit $\times$ feeding level scaling effect. A significant genetic merit $\times$ age scaling effect was observed for protein yield and $A_{0}$, 
Factors affecting the biological parameters of a mammary gland model

Table 2 Descriptive statistics for the mammary gland parameters

\begin{tabular}{|c|c|c|c|c|c|c|}
\hline Mammary gland parameters & No. of observations & Mean & s.d. & CV $(\times 100)$ & Minimum & Maximum \\
\hline$A_{0}\left(\times 10^{10}\right)$ & 150 & 2.06 & 0.19 & 8.98 & 1.33 & 2.46 \\
\hline$k_{1}\left(\times 10^{9}\right.$ per day $)$ & 150 & 1.27 & 0.48 & 37.87 & 0.56 & 2.49 \\
\hline$k_{2}\left(\times 10^{-1}\right.$ per day $)$ & 150 & 2.98 & 0.57 & 19.18 & 0.93 & 3.89 \\
\hline$k_{3}\left(\times 10^{-1}\right.$ per day $)$ & 150 & 3.07 & 1.05 & 34.01 & 2.01 & 5.98 \\
\hline$k_{4}$ (per day) & 150 & 5.79 & 1.07 & 18.48 & 3.56 & 6.99 \\
\hline$k_{5}\left(\times 10^{-2}\right.$ per day $)$ & 150 & 0.80 & 0.57 & 72.13 & 0.08 & 4.48 \\
\hline$L\left(\times 10^{-1}\right)$ & 150 & 3.23 & 0.10 & 3.17 & 3.02 & 3.51 \\
\hline$A_{\text {peak }}\left(\times 10^{10}\right)$ & 146 & 2.34 & 0.08 & 3.25 & 2.22 & 2.61 \\
\hline$A_{\text {mid-late }}\left(\times 10^{10}\right)$ & 149 & 2.25 & 0.06 & 2.71 & 2.12 & 2.44 \\
\hline$A_{\text {produced }}\left(\times 10^{10}\right)$ & 150 & 2.51 & 0.10 & 4.15 & 2.32 & 2.94 \\
\hline
\end{tabular}

the initial population of active alveoli at the start of lactation. The senescence of quiescent alveoli, $k_{5}$, displayed a significant linear effect for genetic merit with lower senescence rates in animals of superior genetic merit. Genetic merit had a significant linear effect on $A_{\text {peak }}$ and $A_{\text {mid-late }}$ with more active alveoli in animals of superior genetic merit (Table 5).

\section{Body condition score at parturition}

Higher BCS at parturition were associated with reduced total lactation yields of milk and protein (Table 4). As expected, BCS at parturition had a significant positive linear effect on live weight around the time of peak milk yield. $A_{\text {produced }} A_{\text {peak }}$ and $k_{3}$ were highest at intermediate BCS of 4.0 to 4.5 (Table 5).

\section{Age}

Age had significant linear and quadratic effects on total lactation yields with yields increased initially up to approximately 8 years of age and declining thereafter (Table 4). Age also had a significant linear effect on $k_{1}$, which influences the rates at which new alveoli are produced, with higher rates in younger animals (Table 5). The reactivation

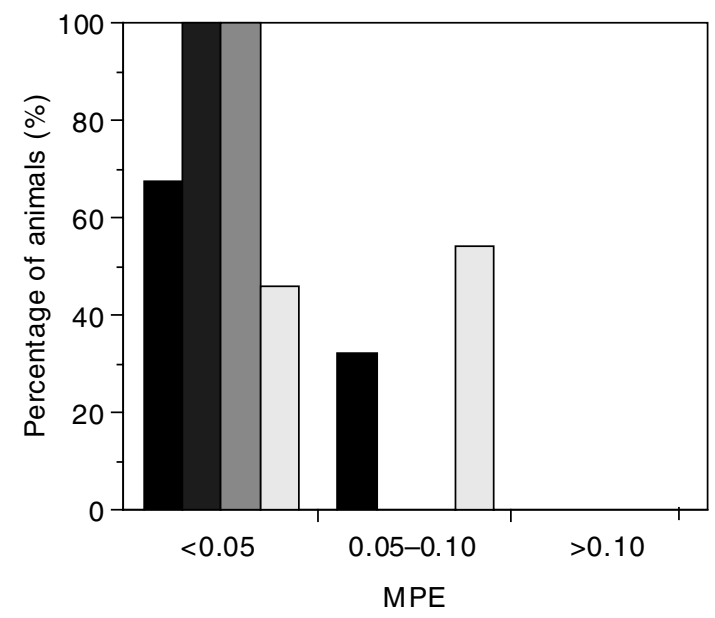

Figure 2 Distribution of mean prediction error (MPE) of predicted $v$. actual values at high $(\square)$, medium $(\square)$, low $(\square)$ and very low $(\square)$ feeding levels. of quiescent alveoli, $k_{4}$, exhibited the same general trend as total lactation yields, with an increase initially up to about 6 years of age but declining thereafter. The total number of alveoli produced from conception until the end of lactation, $A_{\text {produced }}$ declined initially as animals' aged reaching its lower asymptote at 5 years of age but rose thereafter.

\section{Discussion}

The model was able to fit individual lactation curves that corresponded to actual curves with a high degree of accuracy. This was achieved using information related to the nutritional status of the group of cows at each feeding level rather than for individual animals. While it would have been preferable to have an individual estimate of feed intake for each cow, measured by the n-alkane method or calculated from measurements of milk yield, live weight and live weight changes, this was not possible from available data.

Not unexpectedly, some of the mammary gland parameters were correlated (Table 3). The negative correlation between $A_{0}$ and $k_{1}$ indicates that if initial mammary gland cell numbers are higher, then the rate of production of active alveoli by progenitor (undifferentiated) cells is depressed and vice versa. The negative correlation between $k_{3}$ and $k_{5}$ suggests animals with an increased the rate of quiescence of active alveoli $\left(k_{3}\right)$ are also less likely to reactivate quiescent alveoli $\left(k_{5}\right)$. These are probably animals with a high peak, but low levels of persistency. This is further verified through the observed positive correlation between $A_{\text {peak }}$ and $k_{5}$, with higher $k_{5}$ values increasing the rate of senescence of quiescent alveoli. Animals that can reactivate quiescent alveoli need to produce less alveoli throughout lactation, as indicated by the negative correlation between $k_{4}$ and $A_{\text {produced. }}$ Animals with higher initial alveoli numbers, $A_{0}$, are also more likely to have a lower production of active alveoli by progenitor (undifferentiated) cells as mediated through a higher decay constant, $k_{2}$. As expected, higher $k_{1}$ values, which increase the rate of production of active alveoli by progenitor (undifferentiated) cells, increase $A_{\text {produced }}$ and the number of active alveoli in 
Bryant, Lopez-Villalobos, Holmes, Pryce, Pitman and Davis
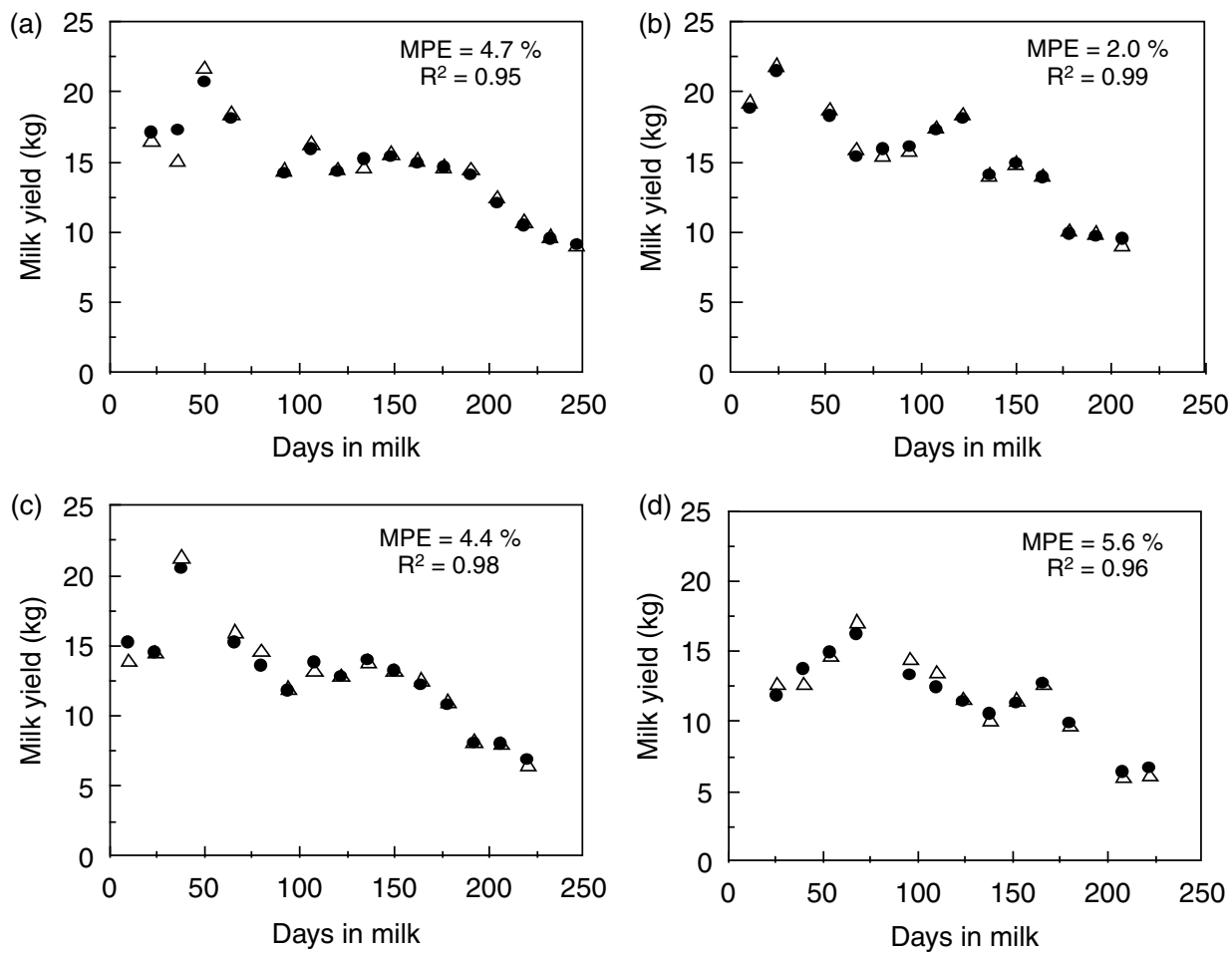

Figure 3 Example lactation curves of predicted $(\Delta)$ and actual $(\bullet)$ milk yields (a) high feeding level, (b) moderate feeding level, (c) low feeding level, (d) very low feeding level. Abbreviations: MPE $=$ mean prediction error, $R^{2}=$ coefficient of determination.

Table 3 Pearson's correlation coefficients between mammary gland parameters

\begin{tabular}{|c|c|c|c|c|c|c|c|c|c|}
\hline & $k_{1}$ & $k_{2}$ & $k_{3}$ & $k_{4}$ & $k_{5}$ & $L$ & $A_{\text {produced }}$ & $A_{\text {peak }}$ & $A_{\text {mid-late }}$ \\
\hline$A_{0}$ & $-0.61^{* \star \star}$ & $0.43^{* * *}$ & -0.02 & -0.14 & 0.11 & -0.11 & 0.14 & 0.09 & 0.06 \\
\hline$k_{1}$ & & 0.14 & 0.15 & 0.01 & 0.03 & 0.00 & $0.35^{* * *}$ & $0.37^{* \star *}$ & $0.31^{\star \star \star}$ \\
\hline$k_{2}$ & & & -0.14 & 0.07 & -0.01 & 0.07 & $-0.17^{*}$ & -0.10 & 0.01 \\
\hline$k_{3}$ & & & & 0.01 & $-0.36^{* * *}$ & -0.08 & $0.37^{* * *}$ & -0.05 & -0.05 \\
\hline$k_{4}$ & & & & & $0.22^{* *}$ & $0.16^{*}$ & $-0.30^{* * *}$ & -0.03 & -0.05 \\
\hline$k_{5}$ & & & & & & -0.11 & $0.22^{\star *}$ & $0.37^{\star \star \star}$ & -0.09 \\
\hline$L$ & & & & & & & $-0.22^{\star \star}$ & -0.14 & -0.02 \\
\hline$A_{\text {produced }}$ & & & & & & & & $0.84^{* * *}$ & $0.61^{* * *}$ \\
\hline$A_{\text {peak }}$ & & & & & & & & & $0.79^{\star \star \star \star}$ \\
\hline
\end{tabular}

Table 4 Significant regression coefficients for feeding level (FL), genetic merit (GM), body condition score (BCS) at parturition and age for milk, fat and protein yield, days in milk and live weight around the time of peak lactation ${ }^{\dagger}$

\begin{tabular}{|c|c|c|c|c|c|c|c|c|c|c|c|c|}
\hline \multirow[b]{2}{*}{ Dependent variable } & \multirow[b]{2}{*}{ Intercept } & \multicolumn{2}{|l|}{$\mathrm{FL}$} & \multicolumn{2}{|c|}{ GM } & \multicolumn{2}{|l|}{ BCS } & \multicolumn{2}{|c|}{ Age } & \multicolumn{2}{|c|}{ Interaction } & \multirow[b]{2}{*}{$R^{2}$} \\
\hline & & $\mathrm{L}$ & Q & $\mathrm{L}$ & $\mathrm{Q}$ & $\mathrm{L}$ & $Q$ & $\mathrm{~L}$ & Q & $\mathrm{FL} \times \mathrm{GM}$ & $\mathrm{GM} \times$ Age & \\
\hline Milk yield $(\mathrm{kg})$ & - & $223.63^{* * *}$ & - & - & - & $-171.89^{* * *}$ & - & $88.03^{* * *}$ & - & $0.139^{* * *}$ & - & 0.99 \\
\hline Fat yield $(\mathrm{kg})$ & $-305.6^{* * *}$ & $31.18^{* * *}$ & - & - & - & - & - & $32.49^{* * *}$ & $-2.26^{* * *}$ & $0.004^{* * *}$ & - & 0.61 \\
\hline Protein yield $(\mathrm{kg})$ & $-97.6^{* *}$ & $19.89^{* * *}$ & - & - & - & $-6.64^{*}$ & - & - & - & - & 0.008 & 0.52 \\
\hline Days in milk & $-158.8^{* * *}$ & $37.23^{* * *}$ & - & - & - & $-12.60^{* * *}$ & - & - & - & - & - & 0.59 \\
\hline Live weight $(\mathrm{kg})$ & $175.4^{* * *}$ & - & - & $0.023^{\ddagger}$ & - & $15.79^{* * *}$ & - & $34.95^{* * *}$ & $-2.13^{\star * *}$ & - & - & 0.50 \\
\hline
\end{tabular}

${ }^{\dagger} \mathrm{L}=$ linear, $\mathrm{Q}=$ quadratic.

${ }^{\ddagger}$ Approaching significance $(P<0.1)$. 
Factors affecting the biological parameters of a mammary gland model

Table 5 Significant regression coefficients for feeding level (FL), genetic merit (GM), body condition score (BCS) at parturition and age for parameters of the mammary gland model ${ }^{\dagger}$

\begin{tabular}{|c|c|c|c|c|c|c|c|c|c|c|c|c|}
\hline \multirow[b]{2}{*}{ Dependent variable } & \multirow[b]{2}{*}{ Intercept } & \multicolumn{2}{|c|}{$\mathrm{FL}$} & \multicolumn{2}{|l|}{ GM } & \multicolumn{2}{|r|}{$\mathrm{BCS}$} & \multicolumn{2}{|c|}{ Age } & \multicolumn{2}{|c|}{ Interaction } & \multirow[b]{2}{*}{$R^{2}$} \\
\hline & & $\mathrm{L}$ & Q & L & Q & L & Q & $\mathrm{L}$ & Q & $\mathrm{FL} \times \mathrm{GM}$ & $\mathrm{GM} \times$ Age & \\
\hline$A_{0}\left(\times 10^{10}\right)$ & $2.03^{* * *}$ & - & - & - & - & - & - & - & - & - & $0.00002^{\ddagger}$ & 0.02 \\
\hline$k_{1}\left(\times 10^{9}\right.$ per day $)$ & $4.32^{* * *}$ & $-0.23^{* * *}$ & - & - & - & - & - & $-0.035^{*}$ & - & - & - & 0.11 \\
\hline$k_{2}\left(\times 10^{-1}\right.$ per day $)$ & $2.99^{* * *}$ & - & - & - & - & - & - & - & - & - & - & 0.00 \\
\hline$k_{3}\left(\times 10^{-1}\right.$ per day $)$ & - & - & - & - & - & $1.48^{* * *}$ & $-0.174^{* * *}$ & - & - & - & - & 0.89 \\
\hline$k_{4}$ (per day) & $5.02^{* * *}$ & - & - & - & - & - & - & $0.317^{*}$ & $-0.026^{*}$ & - & - & 0.03 \\
\hline$k_{5}\left(\times 10^{-2}\right.$ per day $)$ & $96.74^{* * *}$ & $-15.10^{* * *}$ & $0.594^{* * *}$ & $-0.0006^{* *}$ & - & - & - & - & - & - & - & 0.16 \\
\hline$L\left(\times 10^{-1}\right)$ & $2.79^{* * *}$ & $0.04^{*}$ & - & - & - & - & - & - & - & - & - & 0.04 \\
\hline$A_{\text {peak }}\left(\times 10^{10}\right)$ & $9.05^{* * *}$ & $-1.03^{* *}$ & $0.037^{* *}$ & $0.0001^{* * *}$ & - & 0.16 & $-0.020^{*}$ & - & - & - & - & 0.71 \\
\hline$A_{\text {mid-late }}\left(\times 10^{10}\right)$ & - & $0.42^{* * *}$ & $-0.020^{* *}$ & $0.0001^{* * *}$ & - & - & - & - & - & - & - & 1.00 \\
\hline$A_{\text {produced }}\left(\times 10^{10}\right)$ & $3.18^{* * *}$ & $-0.12^{* * *}$ & - & - & - & $0.39^{*}$ & $-0.044^{* *}$ & $-0.025^{*}$ & $0.002^{*}$ & $0.00001^{* * *}$ & - & 0.52 \\
\hline
\end{tabular}

${ }^{\dagger} L=$ linear, $Q=$ quadratic.

${ }^{\ddagger}$ Approaching significance $(P<0.1)$.

peak and mid-late lactation, $A_{\text {peak }}$ and $A_{\text {mid-later }}$ respectively.

The rate at which new alveoli are produced, or cellular proliferation, largely determined by $k_{1}$, was affected by level of feeding, with higher values at lower feeding levels. Similarly, Vetharaniam et al. (2003b) found $k_{1}$ was lower on a diet of essentially ad libitum total mixed ration than high intake levels of pasture. As suggested by Vetharaniam et al. (2003b), it is difficult to explain this result as higher feeding levels or nutrient densities would be expected to increase the proliferation rate of alveoli, as observed by Norgaard et al. (2005). However, it may be that lower levels of feeding prior to parturition in the current study may have suppressed alveoli production and it was not until the animal started lactating that alveoli production was fully activated. Animals on very high feeding levels prior to parturition may have their alveoli population largely fixed at parturition.

Interestingly, $A_{\text {peak }}$ was highest at very low feeding levels. However, this did not result in high milk yields in the very low feeding level environment because milk energy output $(I)$ is a function of the number of active alveoli $\left(A_{t}\right)$, secretion rate per active alveoli $(S)$, energy status $(E)$ and the nutritional buffer factor $(L)$ (equation 17). Therefore, as $E$ is often below unity in a very low feeding level than in a high feeding level environment, milk yields are suppressed in the former compared with latter environment. In addition, low feeding levels have a negative effect on BCS and based on the results presented in Table 5, this would result in a reduction in $A_{\text {peak }}$.

The senescence rate of quiescent alveoli, $k_{5}$, was highest at the very low feeding level. This is consistent with results presented by Knight (2001) for supplemented and un-supplemented cows. However, high $k_{5}$ values were also observed at the highest feeding level. No effect of diet or level of feeding on $k_{4}$ was found in contrast to the results of Vetharaniam et al. (2003b). This suggests a diet effect on $k_{4}$ may be expressed only when two widely different diets are compared e.g. pasture $v$. total mixed ration, or wide ranges of feeding levels are imposed.

In the present study, we observed a genetic merit $x$ feeding level scaling effect for total lactation yields of milk and fat and this is consistent with numerous other studies (Veerkamp et al., 1994; O'Connell et al., 2000; Kennedy et al., 2002). Based on the values presented in Table 4, at feed intakes of 12 and $13 \mathrm{~kg}$ DM per cow that correspond to an approximate average of the present study, we would expect for every $1-\mathrm{kg}$ increase in milk EBV that total lactation yields of milk would increase by 1.67 and $1.81 \mathrm{~kg}$, respectively. This is significantly greater than the theoretical expectation of $1 \mathrm{~kg}$ milk per $1 \mathrm{~kg}$ increase in milk EBV. The scaling effect is possibly due to the overall study environment being superior to the environment which Jersey cows experience in the national herd (Anonymous, 2000). The observed genetic merit $\times$ feeding level scaling effect for $A_{\text {produced }}$ provides a potential mechanism by which scaling effects are expressed at a mammary cell level.

In the present study, the total number of alveoli at peak and mid to late lactation ( $A_{\text {peak }}$ and $A_{\text {mid-later }}$ respectively) increased linearly with genetic merit. Vetharaniam et al. (2003b) reported that a North American Holstein Friesian genotype had lower values for $A_{t}$, than a New Zealand Holstein Friesian genotype when they were managed on pasture. Whereas, on a diet of total mixed ration, $A_{t}$ was higher in the North American than New Zealand Holstein Friesian genotype, indicating a re-ranking type of genotype $\times$ environment interaction. Similarly, re-ranking between genotypes managed on the different diets was observed for $k_{3}$, $k_{5}$, and $A_{\text {produced }}$. The re-rankings for the parameters were consistent with the significant re-ranking for milk solids yields (genetic merit) exhibited by the two genotypes when managed on diets of either pasture or total mixed ration (Kolver et al., 2002) but significant only for $k_{3}$. Davis et al. (1985) found udder volume, theoretically correlated to the population of active alveoli (i.e. $A_{t}$; see Figure 1), was significantly greater in high than low genetic merit Jersey 
cattle. In Friesian cattle, udder volume did not differ between low and high genetic merit groups, but secretory output per active alveoli was significantly greater in the high genetic merit group. Based on the results of this study and previous studies, higher genetic merit animals in a particular environment achieve higher yields through greater pools of active alveoli throughout lactation $\left(A_{t}\right)$, or increased secretory output per active alveolus, elevated levels of persistency (i.e. flatter lactation curve), and higher levels of total alveoli produced from conception until the end of lactation than low genetic merit animals.

In the present study, increased BCS at parturition resulted in reduced total yields of milk and protein. We also observed that animals at intermediate BCS of 4.0 to 4.5 at parturition had the highest values for $A_{\text {produced }}$ and $A_{\text {peak. }}$. However, the rates of active alveoli proceeding to quiescence $\left(k_{3}\right)$ were highest at intermediate BCS at parturition. Waltner et al. (1993) found total lactation yields were reduced at very high and low BCS compared with intermediate BCS. Heuer et al. (1999) and Domecq et al. (1997) found higher BCS at parturition did not increase total lactation yields or yields to 120 days of lactation, respectively. While, the benefits of higher BCS at parturition on milk yields appear to be minimal, there may be a confounding effect of genetic merit (Waltner et al., 1993). For example, there is a negative genetic correlation between BCS and milk yields, meaning animals which are genetically fatter, achieve lower milk yields than genetically thin animals (Pryce et al., 2001; Veerkamp et al., 2001; Coffey et al., 2004). Due to the confounding effects of genetic merit and the low number of animals in the present study we cannot make any definite conclusions on a BCS at parturition, which will optimise milk yields or the number of active alveoli throughout lactation.

We observed increased yields of fat up to 8 years of age but decreases thereafter. Initial rates of differentiation of progenitor cells, $k_{1}$, declined with age. The reactivation of quiescent alveoli, $k_{4}$, was greatest in animals of 5 to 8 years of age. The exact mechanisms by which quiescent alveoli are reactivated into secretory alveoli is not certain (Molenaar et al., 1992). Reactivation of quiescent alveoli may be lower in two-year-old animals than 5- to 8-year-old animals because the former are often still partitioning energy towards growth i.e. a trade-off mechanism between milk production and growth. The trade-off mechanism, combined with the expected reduction in mammary tissue for animals at lower live weights (Linzell, 1972), could also explain the significantly reduced total lactation yields in two year-old animals. Our results, do not provide compelling evidence to explain the findings of previous empirical studies (Varona et al., 1998; Tozer and Huffaker, 1999), where lactation persistency is reduced in older animals than in 2- and 3-year-old animals.

Knight (2000) and Wilde et al. (1997) state that manipulating mammary cell proliferation and senescence holds potential to modify persistency of milk yields. In the present model, genetics of lactation persistency are expressed in a number of the mammary gland parameters, namely $k_{2}$ - $k_{5}$ which control the flow of alveoli from states of active secretory to senescence. We observed from our analyses that cows of superior genetic merit exhibited reduced rates of quiescent alveoli proceeding to senescence $\left(k_{5}\right)$. Vetharaniam et al. (2003b) observed $k_{5}$ was lower on a diet of total mixed ration compared with pasture. Therefore, lactation persistency could be enhanced through the use of energy dense diets (i.e. total mixed ration) and superior genotypes. The potential to select genotypes for lactation persistency was illustrated by Muir et al. (2004), who estimated lactation persistency in first lactation Canadian Holstein Friesians was moderately heritable $\left(h^{2}=0.18\right)$.

\section{Conclusion}

Overall, the results illustrate the model's potential as a tool to fit a lactation curve and to help in understanding the effects of level of feeding or diet, genetic merit, body condition score and age on the dynamics of milk yields during lactation. The next logical progression is to use the derived mathematical functions to assess their ability to accurately predict milk yields for any cow, at any stage of lactation, based on information related to her nutritional status, genetic merit, body condition score and age. Further, studies could also investigate the effect of specific genes on milk yield and milk composition throughout lactation.

\section{Acknowledgements}

The senior author would like to acknowledge the support of an Enterprise Doctoral Scholarship provided jointly by the Livestock Improvement Corporation and the Foundation for Research, Science and Technology. The comments and suggestions of K. Vetharaniam (AgResearch, New Zealand) were greatly appreciated.

\section{References}

Anonymous. 2000. Dairy statistics 1999/2000. Livestock Improvement Corporation. New Zealand, Hamilton.

Broster WH and Broster VJ 1998. Body score of dairy cows. Journal of Dairy Research 65, 155-173.

Capuco AV, Wood DL, Baldwin R, Mcleod K and Paape MJ 2001. Mammary cell number, proliferation, and apoptosis during a bovine lactation: relation to milk production and effect of bST. Journal of Dairy Science 84, 2177-2187.

Coffey MP, Simm G, Oldham JD, Hill WG and Brotherstone S 2004. Genotype and diet effects on energy balance in the first three lactations of dairy cows. Journal of Dairy Science 87, 4318-4326.

Dado RG, Mertens DR and Shook GE 1993. Metabolizable energy and absorbed protein requirements for milk production components. Journal of Dairy Science 76, 1575-1588.

Davis SR, Hughson GA, Bryant AM and Mackenzie DDS 1985. A physiological basis of genetic improvement in milk production of Friesian and Jersey cows. Proceedings of the New Zealand Society of Animal Production 45, 21-25.

Dijkstra J, France J, Dhanoa MS, Maas JA, Hanigan MD, Rook AJ and Beever DE 1997. A model to describe growth patterns of the mammary gland during pregnancy and lactation. Journal of Dairy Science 80, 2340-2354.

Domecq JJ, Skidmore AL, Lloyd JW and Kaneene JB 1997. Relationship between body condition scores and milk yield in a large dairy herd of high yielding Holstein cows. Journal of Dairy Science 80, 101-112. 
Fuentes-Pila J, DeLorenzo MA, Beede DK, Staples CR and Holter JB 1996. Evaluation of equations based on animal factors to predict intake of lactating Holstein cows. Journal of Dairy Science 79, 1562-1571.

Hart RPS, Larcombe MT, Sherlock RA and Smith LA 1998. Optimisation techniques for a computer simulation of a pastoral dairy farm. Computers and Electronics in Agriculture 19, 129-153.

Heuer C, Schukken YH and Dobbelaar P 1999. Postpartum body condition score and results from the first test day milk as predictors of disease, fertility, yield, and culling in commercial dairy herds. Journal of Dairy Science 82, 295304.

Kennedy J, Dillon P, Faverdin P, Delaby L, Buckley F and Rath M 2002. The influence of cow genetic merit for milk production on response to level of concentrate supplementation in a grass-based system. Animal Science 75, 433-445.

Knight $\mathrm{CH}$ 1989. Constraints on frequent or continuous lactation. Proceedings of the Nutrition Society 48, 45-51.

Knight $\mathrm{CH}$ 2001. Lactation and gestation in dairy cows: flexibility avoids nutritional extremes. Proceedings of the Nutrition Society 60, 527-537.

Knight $\mathrm{CH}$ 2000. The importance of cell division in udder development and lactation. Livestock Production Science 66, 169-176.

Knight CH and Wilde CJ 1993. Mammary cell changes during pregnancy and lactation. Livestock Production Science 35, 3-19.

Kolver ES, Roche JR, De Veth MJ, Thorne PL and Napper AR 2002. Total mixed rations versus pasture diets: evidence for a genotype $x$ diet interaction in dairy cow performance. Proceedings of the New Zealand Society of Animal Production 62, 246-251.

Linzell JL 1972. Milk yield, energy loss in milk, and mammary gland weight in different species. Dairy Science Abstracts 34, 351-360.

Mayer DG, Belward JA and Burrage K 2001. Robust parameter settings of evolutionary algorithms for the optimisation of agricultural systems models. Agricultural Systems 69, 199-213.

Mayer DG, Belward JA and Burrage K 1996. Use of advanced techniques to optimize a multi-dimensional dairy model. Agricultural Systems 50, 239-253.

Mayer DG, Belward JA, Widell H and Burrage K 1999. Survival of the fittest genetic algorithms versus evolution strategies in the optimization of systems models. Agricultural Systems 60, 113-122.

Molenaar AJ, Davis SR and Wilkins RJ 1992. Expression of $\alpha$-lactalbumin, a-S1-casein, and lactoferrin genes is heterogeneous in sheep and cattle mammary tissue. Journal of Histochemistry and Cytochemistry 40, 611-618.

Muir BL, Fatehi J and Schaeffer LR 2004. Genetic relationships between persistency and reproductive performance in first-lactation Canadian Holsteins. Journal of Dairy Science 87, 3029-3037.

Neal HD and Thornley JHM 1983. The lactation curve in cattle: a mathematical model of the mammary gland. Journal of Agricultural Science 101, 389-400.
Nielsen HM, Friggens NC, Lovendahl P, Jensen J and Ingvartsen KL 2003. Influence of breed, parity, and stage of lactation on lactational performance and relationship between body fatness and live weight. Livestock Production Science 79, 119-133.

O'Connell JM, Buckley F, Rath M and Dillon P 2000. The effects of cow genetic merit and feeding treatment on milk production, herbage intake and grazing behaviour of dairy cows. Irish Journal of Agricultural and Food Research 39, 369-381.

Phillipi TE 1994. Multiple regression: herbivory. In Design and analysis of ecological experiments (eds SM Scheiner and J Gurevitch), pp. 183-210, Chapman and Hall, New York.

Pollott GE 2004. Deconstructing milk yield and composition during lactation using biologically based lactation models. Journal of Dairy Science 87, 23752387.

Pryce JE, Coffey MP and Simm G 2001. The relationship between body condition score and reproductive performance. Journal of Dairy Science 84,1508 1515.

Statistical Analysis Systems Institute 1999. SAS/STAT users guide, version 8. SAS Institute, Cary, NC.

Tozer PR and Huffaker RG 1999. Mathematical equations to describe lactation curves for Holstein-Friesian cows in New South Wales. Australian Journal of Agricultural Research 50, 431-440.

Varona L, Moreno C, Cortes LAG and Altarriba J 1998. Bayesian analysis of Wood's lactation curve for Spanish dairy cows. Journal of Dairy Science 81, 1469-1478.

Veerkamp RF, Koenen EP. C and De Jong G 2001. Genetic correlations among body condition score, yield, and fertility in first-parity cows estimated by random regression models. Journal of Dairy Science 84, 2327-2335.

Veerkamp RF, Simm G and Oldham JD 1994. Effects of interaction between genotype and feeding system on milk production, feed intake, efficiency and body tissue mobilization in dairy cows. Livestock Production Science 39, 229241.

Vetharaniam I, Davis SR, Soboleva TK, Shorten PR and Wake GC 2003a. Modeling the interaction of milking frequency and nutrition on mammary gland growth and lactation. Journal of Dairy Science 86, 1987-1996.

Vetharaniam I, Davis SR, Upsdell M, Kolver ES and Pleasants AB 2003b. Modeling the effect of energy status on mammary gland growth and lactation. Journal of Dairy Science 86, 3148-3156.

Waltner SS, McNamara JP and Hillers JK 1993b. Relationships of body condition score to production variables in high producing Holstein dairy cattle. Journal of Dairy Science 76, 3410-3419.

Wilde CJ, Quarrie LH, Tonner E, Flint DJ and Peaker M 1997. Mammary apoptosis. Livestock Production Science 50, 29-37.

YearStretch. 2005. YearStretch GASolver, YearStretch Limited (http://www. yearstretch.com accessed: 1 September, 2005.

Yu CH 2000. An overview of remedial tools for collinearity in SAS. Proceedings of the 2000 western users of SAS software conference 196-201. 